EPOS, XIII (1997), págs. 275-287

\title{
LEARNER AUTONOMY IN MODERN LANGUAGES: A DISTANCE LEARNING
}

TRICIA MCERLAIN

C.E.S.S.J. Ramón Carande

This paper seeks to examine the principles of autonomous or self-directed learning, an approach to learning commonly accepted in the fields of Further Education and training, and in Continuing Education generally, and to discuss their application to a distance learning situation within Higher Education, with particular reference to the field of Modern Languages. Without wishing to venture into a discussion on the differences between education and training, which is beyond the scope of this paper, we would argue that these principles, outlined below, form part of the humanistic philosophy of distance learning in Higher Education, and that any situation in which adults are undertaking study for a first or second degree requires an adult-oriented approach to learning. Although the underlying principles outlined below are relevant to any discipline, the specific area to which they are applied here is that of the teaching of languages in distance learning.

The first publications on self-directed learning appeared in the 1970s when Knowles (1975), Tough (1979) and Guglielmino (1977) published a series of works which constituted a new orthodoxy in the field of adult education and which were important in enabling continuing educators to dispel the notion of second-class citizenship frequently associated with adult education, whether in distance learning situations or other forms of continuing education. 
The approaches advocated by the above writers began to take root in the field of EFL in the eighties and various, largely practical, publications of the "howto-set-up - self-access - centres' ilk abounded, as did the jargon employed in the field.

The plethora of terminology in the field of self-directed or autonomous learning requires definition and clarification of terms. We employ the term 'autonomous' here to describe an approach to learning which involves the learner taking responsibility for his or her own learning to a greater degree than has traditionally been the case, at least within the context of Higher Education.

A variety of terminology is employed in the literature to describe ways in which autonomous learning may be carried out and to illustrate techniques of learning and resources for learning, which require explanation.. Equally, the context in which autonomous learning takes place may vary enormously. Here we are concemed with distance learning and the preparation of students of Modern Languages, in a situation which involves both language learning and the study of complementary disciplines, such as Literature and Linguistics or Area Studies. The basic humanistic philosophy of distance learning implies the belief that learning can take place outside the classroom, although Modern Languages has perhaps traditionally been considered as being the most classroombased of disciplines. Technology has facilitated distance language teaching in a way hitherto considered impossible.

Terms frequently used in the context of autonomous learning are:

Individualisation - this term refers to the need to devise an individual programme in accordance with the needs of the student. The circumstances in which this may or may not be possible and the desirability or otherwise of this approach in the context of Higher Education will be discussed later.

Task-based learning - refers to the approach to learning through the accomplishment of relevant tasks. The tasks will obviously vary according to the programme, but in the context of language learning, for example, a simple example might be writing a letter or answering the telephone, as opposed to receiving grammatical instruction. It must be noted that this practical approach to learning lends itself particularly well to language learning.

Resource-based learning - generally refers to the deployment of technology, data bases, inter-active videos etc. which may be used autonomously in the learning situation.

Self-access learning - again, any materials capable of being used without the aid of a teacher. Generally, such materials are self-explanatory and capable of being used in self-assessment, for example by means of an answer key. In a 
language-learning context, the use of self-access centres, providing both printed and multi-media materials in which students can learn without the physical presence of a teacher, is frequent.

Distance learning - implies a necessarily high degree of autonomy, given the physical distance involved. The distance learning mode has become increasingly accepted and valued form of learning both in Europe and throughout the world. Traditionally regarded as the 'poor relation' of orthodox education, it can now be seen as offering unique advantages in its flexibility and adaptability to learner's needs and areas, such as modern languages, previously considered an impossibility may now be taught more effectively through the distance mode, given the ready availability of interactive technology and, more importantly, the increasingly learner-centred philosophy of language learning which encourages a greater degree of autonomy.

In effect, the above terms refer to techniques employed to facilitate learning in a variety of contexts. What underlies them is an approach to learning which starts in the relationship between the teacher and his or her students. The notion of asking questions, rather than providing answers dates from the Greeks and the Socratic ideal of education:

I shall only ask, and not teach him, and he shall share the enquiry with me: and do you watch and see and if you find me telling or explaining anything to him, instead of eliciting his opinion.../...(Socrates)

Indeed, we could venture to say that all real learning is autonomous. Students educated at a traditional British University have been encouraged to learn autonomously and to discuss, through the tutorial system, their reading with their tutor. Lectures may or may not provide a stimulus to reading, but they can never substitute this. The submission of tasks in the form of projects and essays has clearly always been a valuable part of the learning process, what has perhaps been lacking traditionally is the recognition of the role of the teacher as something other than an oracle.

The role of the teacher in any organised programme of autonomous learning, and I am aware of the apparent contradiction in terms inherent in this statement, continues to be important. Again new jargon proliferates and we refer to the teacher as facilitator. Whatever term we use what is important is that the role of facilitator must differ from that of the traditional teacher in the following respects, whatever the context of the programme, whether in a traditional University or in the context of distance learning. 
The role of teacher as facilitator also has implications for the student, which we will discuss later. The principle change which needs to be implemented in order to change the role of the teacher is chiefly one of attitude. Traditionally, the teachers/lecturers have seen themselves as purveyors of information about which they possess a considerable degree of expertise. The reality is that we are all frequently expected, throughout our careers, to teach subjects which have not formed the principle basis of our research and reading. What normally happens is that the teacher employs research skills and communication skills and provides the student with appropriate bibliographies and handouts on the subject concerned and, in effect, encourages the student to work on his/her own on a project or essay or oral presentation. The effect of this is that the student not only gains knowledge of the area concerned, but also acquires valuable study skills and an approach to study which ensures that he/she undertakes responsibility in the learning process.

The question of attitude to learning is, then, crucial to the autonomous learning situation and has implications for the role of the teacher as facilitator and of the student as autonomous learner. Rather than imparting information, the facilitator is encouraging learning. The student, rather than passively receiving knowledge, is actively involved in the learning process. The relationship between the learner and the facilitator is necessarily less hierarchical than formerly and is based on the notion of the learning contract.

The idea of the learning contract, or negotiated programme of studies, should provide the student with a precise description of required behaviour in the learning situation. The facilitator works with the student to establish specific contractual requirements which enable the learner's needs to be met. Clearly, within the context of Higher Education, the formal learning contract is with the degree-awarding institution concerned. Nevertheless, the terms on which a group of students arrange their programme of study may be clarified and their aims specified in such a way as to meet their requirements, encourage their participation in the learning process, while at the same time making them aware of the constraints of time and the availability of the facilitator. During this stage it is important that the student be made aware of the facilitator's role, the degree of support which can be expected and the nature of this support. Equally, it is as well to clarify what should be expected of the student:

../.making the planning of learning experiences a mutual undertaking between a learner and his helper....by participating in the process of diagnosing his needs, formulating his objectives, identifying resources, choosing strategies and evaluating accomplishments the learner develops a sense of ownership of and commitment to the plan. (Knowles 1975) 
Most contracts are variations on Knowles' contracts, illustrated in his book 'Self-directed Learning'. Knowles' contracts are sub-divided into diagnosed learning needs, setting objectives, evidence of accomplishment and criteria for validation and evaluation. Contract learning is by no means a new concept. The first published article concerning contracting was by Helen Parkhurst in 1922. She called her idea the 'The Dalton Laboratory' (after the first place to use the plan). The plan was based on freedom and co-operation, students being encouraged to interact with each other in the exchange of knowledge. The student knew exactly how much work was expected in a given time and was judged on the ability to complete the contract.

Knowles, who focuses on adult learning and has developed a system called 'andragogy', as opposed to 'pedagogy', cautions on the difficulties of contracts in situations where pre-determined competencies are established, such as in Higher Education.. Nevertheless, in a situation where the teaching of adults of all ages is the norm, it is difficult to ignore this adultoriented, student-centred approach. Although in Higher Education the ultimate learning objectives are necessarily pre-established, these overall objectives may be broken down into sub-categories of learning, the process of which may usefully be negotiated. Clearly, if the negotiations allow the student choice in materials and approaches to learning, they have an important role to play in motivating the student to learn, perhaps the most important task of the facilitator. The implications for the degree syllabus and the institutional contract the learner is submitted to is the embodiment of principles of choice, whereby students have the possibility of opting for a variety of 'paths', the viability of which may be discussed with academic advisors. The modular system, in existence in many U.K. Universities and elsewhere, operate in a free market whereby the educational product is on offer and the students, as clients, may opt for that which they feel is most relevant to their needs.

Maslow (1970) saw motivation in terms of a hierarchy of human needs, levels four and five of which refer to the need for self-esteem and self-actualisation. This clearly challenges the facilitator to use this factor to encourage students to work on projects they find personally stimulating, even though this may not coincide with the tutor's personal academic interests. The student must be made aware of the fact that they are responsible for doing their own research and should not rely on the tutor for more than guidance and advice on academic issues, rather than assuming that the tutor will be the sole source of information on the subject.

Knowles presented five underlying assumptions he saw as crucial to the 'androgogical' (adult) learner: 
1. The learner is increasingly self-directed.

2. The learner's experience is a rich resource for learning.

3. The learner's readiness to learn stems from his or her life tasks or problems.

4. Learning itself focuses on tasks or is problem-centred.

In conjunction with these assumptions, Knowles gives six elements necessary for androgical education. These are:

1. establishing a climate conducive to learning,

2. creating a mechanism for mutual planning and mutually formulating objectives.

3. designing a pattern of learning plans involving learning contracts.

4. conducting the learning experience with suitable techniques and resources.

5. evaluating the learning outcomes and re-diagnosing learning needs.

Bruner (1961), in his 'Theory of Discovery Leaming' states "It is participating in the process that makes possible the establishment of knowledge". The androgogical approach to learning, based on the model of self-fulfilment (Maslow 1970) is clearly that which most closely conforms 2 . to thedistance learning model in Higher Education. The following breakdown contains the gist of Knowles' assumptions on pedagogy and androgogy:

pedagogy

age-related decided by biological development and grade level:

curriculum is subject centred

motivation - external pressures

\section{androgogy}

needs related has need to know or do things:

curriculum is task-centred and needsoriented.

motivation internal needs.

Although the aspects of negotiation, necessary to the androgogical approach, are somewhat limited in any situation where pre-determined goals exist, such as a national examination curriculum, clearly there exists scope for negotiated learning objectives at the tutorial level. It is perhaps at this level that an element of negotiation may be introduced and the elements of guidance and negotiation may take place. 
Students can be encouraged to participate in the educational process by giving presentations of their own work or that of a study group working on a particular project. Interest groups can be set up (naturally, they already exist informally) in which students share tasks associated with learning and learn from each other. There is nothing wrong with, and indeed everything to be gained from, a group of students becoming more expert in a particular field than their tutor, whose critical faculties and experience in communicating may be fully exploited by the students. Resistance to such ideas, in my experience, rarely comes from the students, but rather from those teachers who feel insecure about relinquishing authority. The reality is that the facilitator never relinquishes authority but rather employs it differently and in so doing only increases the respect felt for him or her by the students. The major difference is perhaps that the learner, far from being autonomous, is receiving appropriate support . Responsibility for learning is placed on the learner and spoon-feeding is replaced by academic rigour.

Moore (1973:669) has argued that the self-directed learner should not be thought of as an academic Robinson Crusoe castaway and shut-off in self-sufficiency. Adults have at their disposition series of educational broadcasts, books and computer programmes which facilitate learning. Clearly, this is more than ever the case as technology advances. Active student participation in the learning process requires organisation and, above all, the empowerment of students. The fact of having to perform or present material to the peer group is a powerful stimulus to learning as the student who can very happily live without teacher approbation is reluctant to perform badly in front of the peer group, or risk its disapproval by failing to complete his share of the joint task. By the same token, those students who do not complete the task required of them by members of their group risk the benefits accrued from membership - the sharing of materials, tasks, support etc.

Student participation, within the distance learning tutorial system, may usefully consist of:

Individual student presentations of work, both written and oral.

The presentation of handouts, or other classroom materials, on a subject arrived at by negotiation, accompanied either by an oral presentation of the work or, where there may be language problems, such as in a Modern Language course, written submissions which can usefully be distributed amongst the group.

Group presentations of work, oral and written. The same principle applies as in the above, with the sole difference that the group may allot tasks to indi- 
vidual members and those with the most developed language skills will presumably agree to give the oral presentation.

Group projects with feedback in discussion groups. These may consist of something as simple as a comparison of answers to preparatory exam questions, with critical commentaries from the tutor, to a piece of original research requiring library skills and presentation skills. The advantage of the group is the fact that tasks may be shared and the student who does the literature search relies on a fellow student to write up the material. Clearly these projects may take up a great deal of time and the negotiations which take place at the beginning of the course must be realistic in this respect. A single project may take a whole semester, although students can report back on the discreet tasks on a weekly basis, each group member being allotted a slot on the timetable for feedback or presentation.

In a language class, the presentation, depending on the availability of resources, may take the form of making a video or recording a radio interview. The discreet tasks required for each project being negotiated, shared out and time-tabled. As the group is autonomous there is nothing to stop the members from meeting in their own time, indeed the majority of tutorial hours will be used for feedback, rather than preparation, given the constraints of time and resources. Resources are frequently a problem, but public libraries and the students themselves may often make up for shortcomings. Home video cameras are a common resource and the tape recorder is frequently available. Moreover, students who are adequately motivated frequently prove ingenious in developing their own resources and the centre may have to provide little more than a video recorder and a television to allow students to present work produced outside the centre in their own time. The ideal situation, as outlined below, is one in which a resource centre is set up on a self-access basis.

Classes on theory may operate along similar lines with students offering written production in the form of notes or explanatory handouts, O.H.P.s etc. Discipline, naturally, is imposed by the group who may decline to share their work with less productive members. The tutors role is to encourage and evaluate, although peer group evaluation is frequently more effective. It is often useful to evaluate the peer group evaluation, rather than to evaluate the presentation itself, thus allowing valid criticism to remain, while seeking to neutralise comments which may damage the group dynamic.

The fact is that adults enjoy the opportunity to show their skills and to perform, either publicly or by submitting their own work, and are glad to develop skills of self-expression in one form or another. The skills acquired vary from referencing and research skills to public speaking and debating skills and include presentation skills both in their own and in foreign languages, as the ca- 
se may be. Perhaps the most important development is in confidence in their own abilities which must necessarily reflect in their academic work. The tutor facilitates the process by guidance and academic counselling, providing reading lists and perhaps evaluating projects. Of particular importance is the organisation of time as timing and the organisation of a realistic timetable with which all are in agreement is the most difficult of all the aforementioned tasks. Given the nature of the degree course programme, the tutor must also act as coordinator in order to ensure that the overall learning objectives, with pre-determined examination requirements are met. Normally, the students themselves are more than aware of this constraint which acts as a motivating factor in their selection of projects or presentations.

Ideally, these approaches to learning, which represent steps which can be taken on the road to autonomy, should be accompanied by a system of continuous assessment which contributes to the course mark and thereby to success in obtaining credits. On-going assessment is a valuable motivating force in self-directed learning, although the fact that the skills and knowledge acquired are in themselves a preparation for examination success is clearly important.

In the above situations, the role of the tutor is no less central than in a traditional learning situation. The tutor as facilitator is clearly acting as a lynch pin in the organisational process, while allowing students to participate in the classroom. Positive critical evaluation, the overview of timing and selection of tasks and projects, as well as the academic guidance and negotiation are all clearly crucial to the success of the students' activities. At no point, however, does the tutor take the centre-stage, rather encouraging students to do so. In so doing. he/she employs to the full the skills required in the educational process and at the same time helps to dispel the false dichotomy which exists between institutionally arranged learning and learning in informal settings, frequently viewed as being of a lower order. Clearly, what we refer to as 'self-directed learning or autonomous learning' is no such thing within the context of Higher Education, students are clearly supported by teaching staff, but this support takes the form of encouraging the learner to be more independent and participative.

The role of the course co-ordinators, in the distance learning situation, is that of administrator, academic co-ordinator, materials producer and programme designer. As has previously been mentioned, self-directed or autonomous learning within an institutional context is necessarily restricted in so far as the negotiation of ultimate academic goals are concerned. Clearly these are set by the institution, or even the Ministry. Nevertheless, the approach to learning is guided by individual philosophies. We argue here that the autonomous approach to learning is particularly appropriate to the study of languages, given the 
potential role of technology in language acquisition. The course co-ordinator of a Modern Languages degree programme has the task of providing materials and a relevant programme of studies which, unlike other disciplines, must enable the students to acquire language skills, traditionally strongly associated with the classroom and with teacher dependence. Nevertheless, new technology offers a number of potentially interactive situations in which both exposure to the receptive skills may be offered and even, although still in its rudimentary form, the productive skills of speaking and writing may be performed interactively, unaided by the traditional teacher and capable of being used in the home. Examples of these are the following:

\section{Video materials:}

Without being able to offer here a full picture of the potential uses of video in language teaching, it is obviously a means of allowing contextualised exposure to language which students can use within their own homes. The uses vary from language-learning packages, specifically designed to teach the rudiments of the language, to the use of target language videos for the teaching of related disciplines, such as Area Studies. These in themselves provide an optimum means of improving listening speaking skills by providing relevant and contextualised input. The accompanying texts can provide written input, as well as aiding understanding. In the earlier stages of learning, such input can be graded and designed to include self-assessment keys and explanatory notes on grammatical structures, which in turn provide the opportunity of teaching syntax and semantics and of providing students with the opportunity of familiarising themselves with the meta-language of their discipline. Clearly, as we are talking about studying an academic discipline, as well as acquiring language skills, the two must go hand-in-hand.

\section{Computer technology:}

Naturally, it would require a more substantial work than the present to properly exploit the language-learning potential of the $\mathrm{PC}$, but it is unique in one respect, which is its ability to respond interactively with the individual student. Programmes are available which offer features such as voice recognition, whereby student errors of pronunciation are corrected, although somewhat arbitrarily. The simple device of spell-checking improves written production and programmes now exist which help in translation and syntax. Above all, per- 
haps, the availability of internet, primarily of use for those wishing to improve English language skills, is a major incentive to learning for the student who wishes to use this form of communication. The internet network offers opportunities for those possessing hardware, now within the reach of a majority of students, either in their homes or in their centres of study or work, to speak to people in other countries at local rates and to research topics using English. Email offers the possibility of corresponding in foreign languages with native speakers, thus incentivating learning in a way which was inconceivable even five years ago. Clearly, the actual communication taking place is beyond the control of teachers, whose role must clearly be that of setting learning objectives, providing supplementary materials, particularly for beginners who may be unable to cope, and offering the possibility of back-up materials available by computer link.

The principal task facing the course co-ordinator is that of teaching students, many of whom have little previous language learning experience, how to learn. The material packs prepared for students may usefully include, in the initial stages at least, a study skills pack outlining the requisites for the good language learner. The aim of such an introductory package would be to introduce students to the philosophy underlying the methodology. This would require an explanation of the role of the student as an active learner, responsible for meeting set objectives, but free to learn at his/her own speed and in accordance with individual interests. The understanding of the philosophy is vital to the success of the programme and, at this stage, the tutorial system comes heavily into play - not in order to teach language skills, as such, but rather to explain to students the approach to learning which is envisaged and show them how to learn.

The specific case in point, that of language learning, lends itself to this approach, as we have pointed out, as the students will be required to understand how to employ technology in language learning, what attributes the 'good language-learner' should acquire, the link between input and output, i.e. the more you listen the better you will speak, the more you read, the better you will write. The use of listening materials to improve pronunciation, the need to use grammatical reference books and the use of dictionaries can all be included. Non-language related skills, such as note-taking, referencing and general library skills are also important.

Ideally, as we are envisaging here a situation in which students will be studying related disciplines, such as Linguistics, an introduction to Linguistics should complement the study skills course in order to prepare students for the theoretical side of language, which in turn will enable them to become more sophisticated language learners. The emphasis in the study skills courses 
should be on participation and the approach task-oriented. Obviously, study skills tutorials should preferably take place in a fully-equipped self-access centre containing the relevant materials and technology which would allow students to understand the possible uses of these resources in their own homes. The self-access tutorial centre would contain listening booths and audio-visual resources, PCs with access to internet and with appropriate CD ROM language learning packages, as well as written source materials of a variety of registers and levels: graded readers, target language newspapers and magazines etc. These centres should allow access to students who lack their own technology and the possibility of operating a booking system, allowing each student to have access is desirable.

Materials in such a centre would require a major investment of time and money, given that they must be clearly graded, self-explanatory and capable of self-assessment. They should also be varied and stimulating. The tutor's time in this system is employed largely in such material production, as well as being available for academic guidance. The students may be encouraged to complement these activities by forming conversation groups, at British Universities such groups are led by foreign language assistants who allow the students the opportunity to practice with native speakers of the target language.

There are various systems for self-instruction in language learning in operation in European Universities. That run by CRAPEL (Centre de Recherche et d'Applications Pedagogique en Langues) at the University of Nancy II provides facilities for self-directed learners of English both from within the University and from extra-mural groups. CRAPEL have an ideological commitment to self-instruction and offer a choice between an autonomous course and a 'normal' class, which simultaneously prepares them for autonomy. Modules based on a cyclical syllabus are offered dealing with a particular function of English. Total autonomy of the learner is the ultimate aim, although initially a 'helper' is available to introduce students to the system. A sound and video library is available, although normally technicians can copy materials onto the student's cassette for home use. Self-assessment is employed which allows students to judge their own performance, based on such criteria as degree of understanding, successful accomplishment of tasks, and so on.

The Open Access Sound and Video Library at the University of Cambridge, began in 1966 offers language learning facilities to members of the University. The facility is open to both staff and students who have a variety of needs, ranging from foreign holidays to field work in foreign countries. The majority of users are non-linguists and the aim of both the Cambridge and the CRAPEL system differs from the situation outlined in this paper as in neither case is the centre used for preparing students for Modern Language Degrees. 
The self-access resource centre is complemented with an advisory centre offering tutorial guidance. The centre caters for over one hundred languages with a range of different courses catering for a variety of levels and needs. A selfexplanatory kit is available to help students familiarise themselves with the centre. It contains leaflets giving advice and information on the catalogue and information on how to make use of authentic documents. The kit also contains a leaflet on motivation, aims and, functions and information which questions the learner about his reasons for learning a language. Alternatively a learner planning to use the library may go straight to the advisory centre without visiting the Sound and Video Library.

The British Council DTEO Direct Teaching of English Operation designed a self-access system which would cater for adult learners with specific needs for English, whose entry level s vary from beginner to advanced. The idea devised offers performance charts and networks, maps allowing the learner to find out where he is and where he wishes to go. The network is a set of related language modules which enables the learner to progress from one to another while providing an element of choice. (Dickinson 1987)

So far these techniques have been successfully applied to situations where language learning does not form part of a degree programme. There would appear to be no reason why student-centred language learning should not prove equally successful. on such a programme The general philosophy of autonomous learning is valid in any educational context, although the degree to which it is implemented and the techniques employed must inevitably vary. In the distance learning of languages it can only be seen as a felicitous coincidence between good practice and institutional needs.

\section{WORKs CITED}

BRUNER. J. (1961). "The act of discovery" in Harvard Education Review, Vol. 31. N. ${ }^{\circ}$ 1, p. 23.

DickINSON. L. (1987). Self Instruction in Language Learning. C.U.P. Pp. 43-50.

KNOWLES (1975). Self-Directed Learning: a guide for learners and teachers. New York: Cambridge Books.

MasLow A.H. (1970). Motivation and Personality. New York: Harper and Row. Tough, A.M.. (1979). The Adult's Learning Project: a fresh approach to theory and practice in adult learning. (2nd ed.). Texas: Learning Concepts. 